\title{
3D finite element model for predicting manufacturing distortions of composite parts
}

\author{
Kenan Çınar' and Nuri Ersoy ${ }^{2}$
}

\begin{abstract}
A 3D finite element model has been developed for predicting manufacturing distortions of fibre-reinforced thermosetting composite parts. The total curing process is divided into three steps that correspond to the states that resin passes through during curing: viscous, rubbery, and glassy. Tool-part interaction properties were calibrated by modelling the distortion of a single ply part. For comparison, composite parts of various geometries (L-section and U-section), stacking sequences, thicknesses, and bagging conditions were manufactured. The full field thickness profile and full field distortion pattern were obtained using a 3D laser scanner, which reveals higher and lower resin bleeding and corner thickening locations. The effect of stacking sequence is also examined with the full field distortion pattern. It was found that the parts manufactured under the bleeding condition give higher spring-in and warpage values. The spring-in predictions were well matched to measurements of the manufactured parts.
\end{abstract}

\section{Keywords}

Thermosetting resins, residual/internal stress, finite element analysis, autoclave

\section{Introduction}

Manufacturing shape distortions in fibre-reinforced composite materials still remain important, because no method has been developed to entirely eliminate these distortions. To overcome this problem, analytical and numerical methods have been proposed to predict an optimum mould geometry that results in minimal problems during the assembly stage. Different mechanisms such as material anisotropy, cure shrinkage, toolpart interaction, and resin flow have an effect on residual stresses and distortions. Some of these mechanisms occur from the beginning to the end of the manufacturing process, while others occur only at certain stages. ${ }^{1}$ Due to this complexity, early studies developed sophisticated process models using laminated plate theory (LPT) to simulate the curing process of continuous fibre-reinforced composite materials. ${ }^{2-6}$ Loos and Springer ${ }^{6}$ developed a process model for curing of flatplate composites. The integrated sub-model approach was introduced to divide this complex problem into simple sub-models. White and $\mathrm{Hahn}^{2,3}$ and Bogetti and Gillespie ${ }^{4,5}$ also used the integrated sub-model approach to predict the process-induced stress and deformations. Bogetti and Gillespie ${ }^{5}$ developed a onedimensional cure simulation analysis coupled to a LPT analysis of thick composites, including temperature gradients through thickness, spatially varying curedependent mechanical properties, thermal expansion, and chemical shrinkage strains. White and $\mathrm{Hahn}^{2,3}$ developed a process model which predicts a residual stress history during curing of composite materials by including the effects of chemical and thermal strains. They combined the cure kinetics and viscoelastic stress analysis to calculate residual moment and in turn find the curvatures simultaneously. Arafath et al. ${ }^{7,8}$ developed a closed-form solution based on theory of elasticity for process-induced stresses and deformations in flat and curved composite structures.

LPT-based models were restricted to use simplified mechanical boundary conditions, precluding

\footnotetext{
'Mechanical Engineering Department, Namık Kemal University, Turkey ${ }^{2}$ Mechanical Engineering Department, Bogazici University, Turkey

Corresponding author:

Kenan Çınar, Mechanical Engineering Department, Namık Kemal University, Çorlu, Tekirdag, Turkey.

Email: kcinar@nku.edu.tr
} 
application to relatively complex-shaped parts. Johnston et al. ${ }^{9}$ developed a 2D plane strain finite element (FE) model which employs a cure hardening, instantaneous linear elastic (CHILE) constitutive model to predict process-induced stress and distortions of composite laminates. The model examined the effect of thermal expansion, cure shrinkage, temperature gradients, degree of cure, resin flow, and mechanical constraints on the deformation of the laminates using an integrated sub-model approach. In their study, Svanberg and coworkers ${ }^{10-12}$ developed a simplified mechanical constitutive model to predict the shape distortions. They assumed that the mechanical behaviour of the material is constant within the rubbery and glassy states, and there is a step change in the properties at the glass transition temperature. The rubbery properties they used were simply assumed to be about two orders of magnitude smaller than those in the glassy state. The main drawbacks of their numerical analysis were that there was no experimental data about the rubbery properties and that the tool-part interaction was oversimplified. A comparison between experimental and predicted shape deformations indicated that after the second cure step, the predicted spring-in agreed well with the experimental values, but after the third cure step, the prediction was poor. Their predictions overestimated the spring-in angle after the third cure step. Ersoy et al. ${ }^{13}$ developed a 2D two-step FE model including anisotropy in the thermal expansion coefficient and cure shrinkage to predict the processinduced stress and deformation. The two-step model represented the rubbery and glassy states of the resin. In each step, constant material properties were used. Gelation and vitrification were considered to be the two main transitions during the curing process. The change of resin properties in the rubbery state was predicted by using group interaction modelling (GIM), and the mechanical properties of the composite were predicted through the two different micromechanics methods, namely, self-consistent field micromechanics (SCFM) and finite element-based micromechanics (FEBM). The properties of the composite in the glassy state were determined both experimentally and numerically. Spring-in values predicted by the two-step finite element analysis (FEA) were very close to the measurements for both unidirectional and cross-ply C-shaped composite parts. Çinar et al. ${ }^{14}$ extended the FE procedure developed by Ersoy et al. ${ }^{13}$ to include tool-part interaction in order to predict the manufacturing distortions of corner sections. The effect of various material and geometric variables on the deformation of Lsection parts was investigated by a Parameter Sensitivity Analysis. ${ }^{14}$ Çınar and Ersoy ${ }^{15}$ also performed a 2D FEA of composite parts using a fourstep model to investigate the effect of fibre wrinkling on the spring-in. In the first step, fibre conformation to tool surface was integrated in the model. It was observed that the parts that have more fibre wrinkling have lower spring-in values.

Some 3D process models have also been developed to predict the shape distortions. ${ }^{16-19} \mathrm{Zhu}$ et al. ${ }^{16}$ developed a three dimensional coupled thermo-chemo-viscoelastic model to simulate the heat transfer, curing, residual stresses, and deformation of thin flat and L-shaped composite laminates. It was found that thermo-chemo-viscoelastic model gave much larger spring-forward values as compared to the elastic or viscoelastic models that only accounts for the cooldown process. Bogetti and Gillespie's ${ }^{5}$ integrated submodel approach was used in the study of Tavakol et al. ${ }^{18}$ A 3D coupled thermo-mechanical FE model included cure kinetics, cure shrinkage, thermal strains, tool-part interaction, and the development of mechanical properties during curing. A square flat laminate was manufactured to validate the simulations. The predictions and experimental results for the maximum distortion and deformation pattern were in good agreement. A tooling geometry optimization was done by Wucher et al. ${ }^{19}$ for compensation of cure-induced deformations. A doubly curved C-spar geometry was optimized to minimize process-induced deformations by a control points method; the residual distance between the current position of the control points and their nominal position is measured after a best-fit alignment. However, the approach was not validated experimentally.

Some other approaches were also used for predicting process-induced stresses and deformations. ${ }^{20,21}$ Dong $^{20}$ introduced a piece-wise approach for calculating the shape changes of curved composite parts by dividing the curved structure into a number of pieces and calculating deformations using effective coefficient of thermal expansions (CTEs). The approach was validated by FEA, and satisfactory results were obtained. Kappel et al. ${ }^{21}$ used a semi-numerical methodology to predict cure-induced distortions with a combination of experimental, analytical, and numerical procedures. Experimentally determined spring-in values of L-shaped parts were implemented in an FE model for calculating deformations of more complex parts. By this method, the deformation pattern of a box-shaped structure was predicted.

Generally two methods have been used to include the tool-part interaction phenomenon in the processing models. These are the cure hardening elastic shear layer method and the Coulomb friction model. In the shear layer method, the tool and the part remains intact until the tool is removed. ${ }^{7-9,22,23}$ By adjusting the shear layer properties such as elastic and shear modulus, the amount of stress transferred between the tool and 
part can be tailored and a range of tool-part interface conditions can be simulated. According to a parametric study $^{23}$ using this shear layer model, the tool-part interfacial shear stress distribution is critical for accurate modelling of distortions. Arafath et al. ${ }^{7,8}$ also used the shear layer assumption in a closed-form solution for process-induced stresses and deformations for flat and curved geometries. In some studies, ${ }^{14,15,24,25}$ the interfacial shear stress was assumed to obey the Coulomb friction model, ${ }^{26}$ where the interfacial shear stress is proportional to the contact pressure with the friction coefficient as the constant of proportionality. The proportionality is maintained until a critical shear stress is reached, after which sliding with constant shear stress is observed. The tool-part interaction was modelled either as an interfacial sliding friction at the interface, ${ }^{14,15,24,25}$ or it is assumed that the part stuck to the tool surface without any relative motion. ${ }^{16}$

To present, most of the work has focused on twodimensional models. Three-dimensional process models for composite materials are rather rare due to the complexity of the problem. Observations of manufactured composite parts show that the deformation of L-and U-shaped parts is not constant along the length direction, meaning that a $2 \mathrm{D}$ section plain strain (or generalized plane strain) model does not represent the true nature of the deformation. This study develops a 3D three-step model to predict the shape distortions for $\mathrm{L}$ and U-shaped parts with different stacking sequences and thicknesses. A new method is introduced for the calibration of the tool-part interaction properties used in the Coulomb friction model. Finally, the effects of the bagging condition on the thickness distribution and the effect of stacking sequence under the bleeding condition were examined.

\section{Experimental procedures}

\section{Material and manufacturing}

The material used was a unidirectional carbon-epoxy prepreg material produced by Hexcel composites with a designation of AS4/8552. The nominal thickness of the single prepreg was specified as $0.184 \mathrm{~mm}$ with a nominal fibre volume fraction of $57.4 \%$. The mould was a U-shaped steel tool made of IMPAX P20 Hot Work tool steel with a CTE of $12.6 \mu \mathrm{m} / \mathrm{m}-{ }^{\circ} \mathrm{C}$. The dimensions and shape of the mould are represented in Figure 1. The L- and U-shaped parts were manufactured in this U-shaped steel tool.

The manufacturing of the composite parts was done by hand cutting and hand lay-up of prepregs. Two types of vacuum bagging arrangements were used, shown in Figure 2. For both arrangements, a Tefloncoated glass fabric release film with a thickness of

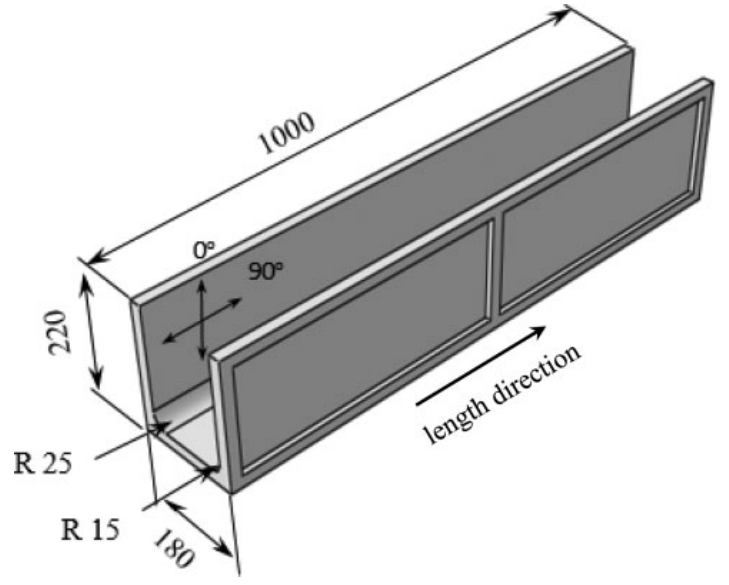

Figure I. Dimensions and shape of mould (dimensions are in $\mathrm{mm})$.

$0.08 \mathrm{~mm}$ was applied over the entire surface of the tool, allowing for easy removal of cured parts and good slip of the prepreg on the tool. Then, each ply was carefully laid-up on one side of the mould to form an L-shaped stack or laid-up on both sides of the mould to form a U-shaped stack.

- For the first vacuum bagging arrangement, one layer of Teflon-coated glass fabric release film was placed on the top of the prepreg stack. A breather was used on the release film to provide a path for the flow of any trapped air in the laminate during the cure cycle. Then a vacuum bag and a sealant tape were applied to seal the whole stack.

- For the second vacuum bagging arrangement, one layer of peel ply was placed on the top of the prepreg stack. A breather was used on the peel ply to absorb any excess resin that bled from the laminate. Then a vacuum bag and a sealant tape were applied to seal the whole stack.

To remove any entrapped air and to minimize the possible effect of corner bridging, a vacuum of approximately -0.9 bars was applied after laying up the samples. Finally, the parts were cured according to the manufacturer's recommended cure cycle (MRCC) for AS4/8552. After processing, the mould was left to cool down to ambient temperature before the composite part was removed from the mould. The samples manufactured are listed in Table 1.

\section{Measurement of part geometry}

The full field thickness profile and full field distortion pattern were obtained using a 3D laser scanning method. To obtain a full field thickness profile, the 

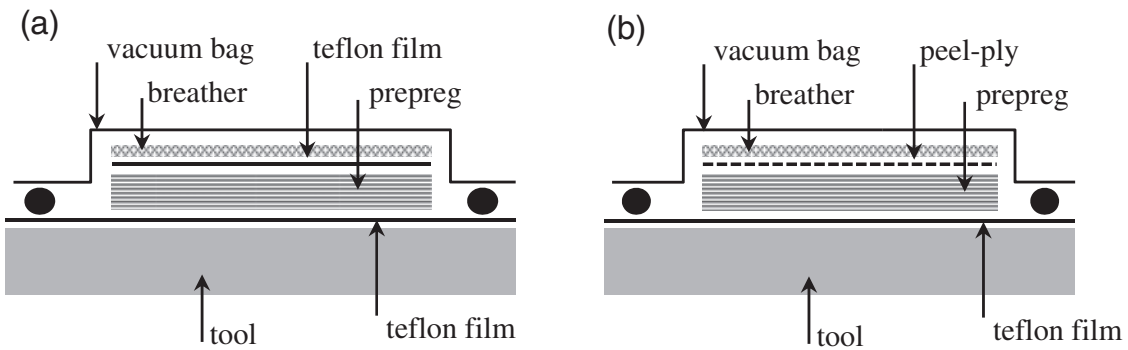

Figure 2. Bagging arrangement: (a) non-bleeding condition and (b) bleeding condition.

Table I. Samples manufactured.

\begin{tabular}{|c|c|c|c|c|c|c|}
\hline \multirow{2}{*}{ Designation } & \multirow{2}{*}{ Geometry } & \multicolumn{2}{|c|}{ Dimension (mm) } & \multirow{2}{*}{ Bagging condition } & \multirow{2}{*}{ Stacking sequence } & \multirow{2}{*}{ Quantity } \\
\hline & & Radius & Width & & & \\
\hline UD4-RI5 & L-shaped & 15 & 150 & Non-bleeding & {$[0]_{4}$} & 3 \\
\hline UD4-RI5 & L-shaped & 15 & 150 & Bleeding & {$[0]_{4}$} & 3 \\
\hline XP4-RI5 & L-shaped & 15 & 150 & Non-bleeding & {$[0 / 90]_{s}$} & 3 \\
\hline XP4-RI5 & L-shaped & 15 & 150 & Bleeding & {$[0 / 90]_{s}$} & 3 \\
\hline UD8-RI5 & L-shaped & 15 & 150 & Bleeding & {$[0]_{8}$} & I \\
\hline XP8-RI5 & L-shaped & 15 & 150 & Bleeding & {$[0 / 90]_{2 s}$} & I \\
\hline UDI2-RI5 & L-shaped & 15 & 150 & Bleeding & {$[0]_{12}$} & I \\
\hline XPI2-RI5 & L-shaped & 15 & 150 & Bleeding & {$[0 / 90]_{3 \mathrm{~s}}$} & I \\
\hline UDI6-RI5 & L-shaped & 15 & 150 & Bleeding & {$[0]_{16}$} & I \\
\hline XPI6-RI5 & L-shaped & 15 & 150 & Bleeding & {$[0 / 90]_{4 \mathrm{~s}}$} & I \\
\hline UD4-R25 & L-shaped & 25 & 150 & Non-bleeding & {$[0]_{4}$} & 3 \\
\hline UD4-R25 & L-shaped & 25 & 150 & Bleeding & {$[0]_{4}$} & 3 \\
\hline XP4-R25 & L-shaped & 25 & 150 & Non-bleeding & {$[0 / 90]_{\mathrm{s}}$} & 3 \\
\hline XP4-R25 & L-shaped & 25 & 150 & Bleeding & {$[0 / 90]_{\mathrm{s}}$} & 3 \\
\hline UD8-R25 & L-shaped & 25 & 150 & Bleeding & {$[0]_{8}$} & I \\
\hline XP8-R25 & L-shaped & 25 & 150 & Bleeding & {$[0 / 90]_{2 \mathrm{~s}}$} & I \\
\hline UDI2-R25 & L-shaped & 25 & 150 & Bleeding & {$[0]_{12}$} & I \\
\hline$X P I 2-R 25$ & L-shaped & 25 & 150 & Bleeding & {$[0 / 90]_{3 \mathrm{~s}}$} & I \\
\hline UD16-R25 & L-shaped & 25 & 150 & Bleeding & {$[0]_{16}$} & I \\
\hline XP16-R25 & L-shaped & 25 & 150 & Bleeding & {$[0 / 90]_{4 \mathrm{~s}}$} & I \\
\hline XP4-RI5 & L-shaped & 15 & 150 & Bleeding & {$[90 / 0]_{\mathrm{s}}$} & I \\
\hline Single ply & L-shaped & 15 & 150 & Non-bleeding & {$[0]$} & I \\
\hline UD4-Long & U-shaped & $15-25$ & 500 & Bleeding & {$[0]_{4}$} & I \\
\hline XP4-Long & U-shaped & $15-25$ & 500 & Bleeding & {$[0 / 90]_{\mathrm{s}}$} & I \\
\hline
\end{tabular}

bag and tool side of the parts were scanned, with the difference regarded as the thickness on the part. To obtain a full field deformation pattern, only the toolsided surfaces of the specimens were scanned. The point cloud obtained by scanning the surface of the part was then virtually placed on the nominal tool surface using three edge points, and the gap distances between the tool and the part were obtained at discrete points over the surface as shown in Figure 3(a). In order to calculate spring-in values, gap distances were read on both flanges at five equally spaced points along five stations, as indicated in Figure 3(b). The spring-in angle was measured by drawing secant lines on the arms. Single point accuracy of $3 \mathrm{D}$ laser scanning is $0.025 \mathrm{~mm}$ which corresponds to a precision of $0.014^{\circ}$ in terms of spring-in for the geometry of the parts measured in this study.

\section{Finite element analysis}

A 3D three step model was developed to predict the distortions due to processing using the basic process 
(a)

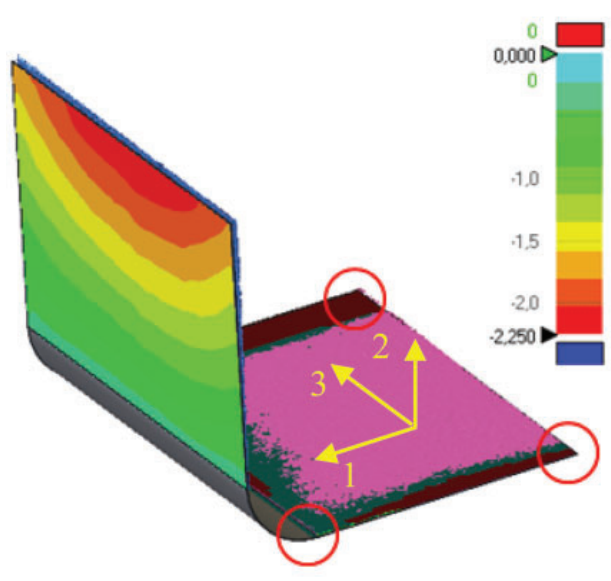

(b)

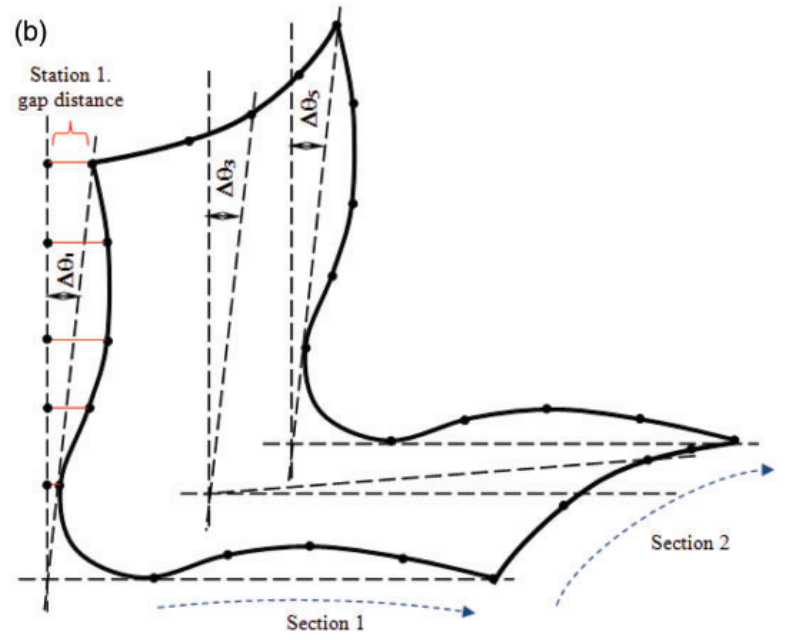

Figure 3. (a) Full field deformation pattern (the scale is in $\mathrm{mm}$ ). (b) Schematic representation.

model previously developed and implemented in ABAQUS by Ersoy et al. ${ }^{13}$ and Çınar et al. ${ }^{14}$ In this model, the mechanical properties were assumed to be constant within each of the viscous, rubbery and glassy material phases, and the mechanical properties of a single lamina were assumed to be transversely isotropic.

\section{Steps of analysis}

The first step of the model (Step 1) includes viscous properties of the composite. It is difficult to measure the properties in this step, and there are no data in the literature related to the viscous behaviour. Following the previous parametric study of Çınar et al., ${ }^{14}$ the shear modulus in this step is assumed to be reduced by a factor of 5 . The material in this step is assumed to be linear elastic. In Step 2, the rubbery mechanical properties calculated previously by micromechanics ${ }^{27}$ are used. Due to cross-linking reactions, contraction occurs through the thickness direction in the rubbery step. To obtain the experimentally measured $0.48 \%$ transverse cure shrinkage in this step, ${ }^{28}$ an equivalent negative CTE is used as given in Table 2. In Step 3 of the model, the properties of the material are switched to the glassy properties. In a previous study, ${ }^{14}$ it has been shown that the effect of thermal contraction on spring-in does not change significantly by corner thickening, as shown by the approximately constant values for the different thickness cases with different degrees of corner thickening. Hence, the effect of corner thickening has not been included in this study, and nominal values of CTE are used. In Step 1 and Step 2, an autoclave pressure of $0.7 \mathrm{MPa}$ is applied to the surfaces on the bag side of the part. In Step 3, the applied pressure is removed, the part is allowed to separate from the tool, and deformations develop. In all the three steps, a uniform
Table 2. Material properties used in the model. ${ }^{13,14}$

\begin{tabular}{lllll}
\hline & & Viscous $^{\mathrm{b}}$ & Rubbery & Glassy \\
\cline { 3 - 5 } Property & Unit & & $\left(20 \rightarrow 165^{\circ} \mathrm{C}\right)$ & $\left(165 \rightarrow 180^{\circ} \mathrm{C}\right)\left(180 \rightarrow 20^{\circ} \mathrm{C}\right)$ \\
\hline $\mathrm{E}_{11}$ & $\mathrm{MPa}$ & 132,200 & 132,200 & 135,000 \\
$\mathrm{E}_{22}=\mathrm{E}_{33}$ & $\mathrm{MPa}$ & 165 & 165 & 9500 \\
$\mathrm{G}_{12}=\mathrm{G}_{13}$ & $\mathrm{MPa}$ & $44.3 / 5$ & 44.3 & 4900 \\
$\mathrm{G}_{23}$ & $\mathrm{MPa}$ & $4 \mathrm{I} .6 / 5$ & 41.6 & 4900 \\
$v_{12}=v_{13}$ & - & $0^{\mathrm{a}}$ & 0.346 & 0.3 \\
$v_{23}$ & - & $0^{\mathrm{a}}$ & 0.982 & 0.45 \\
$\alpha_{11}$ & $\mu \varepsilon /{ }^{\circ} \mathrm{C}$ & $0^{\mathrm{a}}$ & $0^{\mathrm{a}}$ & $0^{\mathrm{a}}$ \\
$\alpha_{22}=\alpha_{33}$ & $\mu \varepsilon /{ }^{\circ} \mathrm{C}$ & 32.6 & -320 & 32.6 \\
$\varepsilon_{11}^{\text {cure }}$ & $\%$ & $0^{\mathrm{a}}$ & $0^{\mathrm{a}}$ & $0^{\mathrm{a}}$ \\
$\varepsilon_{22}^{\text {cure }}=\varepsilon_{33}^{\text {cure }}$ & $\%$ & $0^{\mathrm{a}}$ & 0.48 & $0^{\mathrm{a}}$ \\
\hline
\end{tabular}

${ }^{\mathrm{a}}$ Assumed to be zero.

bValues were assumed.

temperature is assigned to the parts because the temperature range measured across the thickness and in the plane of the part at eight stations is within a $3^{\circ} \mathrm{C}$ band, even for the thickest (16 plies) laminates. The change of material properties from one step to the next is implemented in the analysis by means of ABAQUS User Material subroutine (UMAT), which updates the elastic properties at the beginning of each step, and the stresses locked-in at each step are added up to find the final stress state after removal from the mould. Interactions between the tool and the part were modelled using a Coulomb friction model. The maximum sliding shear stress $\tau_{\max }$ and the friction coefficient $\mu$ were assumed to be the same for the two in-plane directions and found by calibrating the model. The toolpart interaction was explained in detail in a previous 2 D three-step study. ${ }^{14}$ 


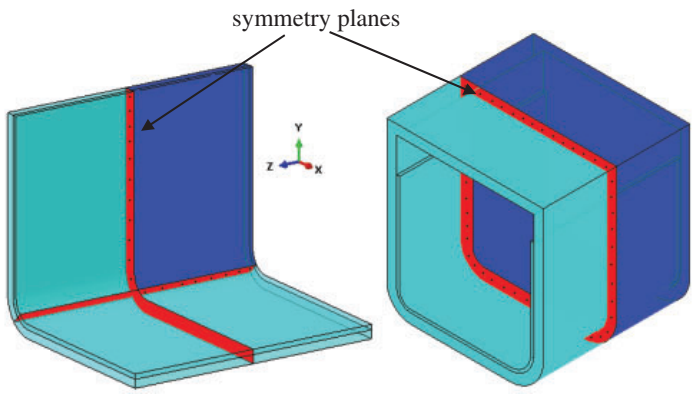

Figure 4. 3D modelling of L- and U-shaped parts.

\section{Meshing and boundary conditions for L- and $U$-section parts}

L-section parts were modelled with one-quarter of the full part and U-section parts were modelled with half of the full part by using mirror symmetry boundary conditions. The symmetry planes are shown in Figure 4. Because of the unequal radii on the two corner sections, there is only one symmetry plane for U-section parts.

The sliding boundary conditions on the back side of the tool enable the tool to expand or contract along the in-plane directions $(Y$ and $Z)$ in the flat section, and along the tangential $(T)$ and axial $(Z)$ directions in the curved region, but prevent free body motion of the tool for L-section parts. For U-section parts another sliding boundary condition was assigned to allow the bottom of the tool to expand or contract freely along the inplane directions ( $X$ and $Z$ ). The tool-part interaction is sliding with constant shear stress as explained in previous sub-section and was assumed to be the same for the two in-plane directions. The autoclave pressure was applied as a surface pressure on the laminate. The boundary conditions can be seen for both L- and U-sections in Figure 5.

Each ply was represented by one element through the thickness. A 4-ply laminate is shown in Figure 6. 8-Node Linear Brick Elements (C3D8) and 20-Node Reduced Quadratic Brick Elements (C3D20R) were used.

A convergence study was performed to find an appropriate mesh size. The central processing unit (CPU) times and deformation at the tip of mid-section of the laminate were compared when using C3D8 and C3D20R elements for a UD4-R25 sample (unidirectional 4-ply thick L-section with $25 \mathrm{~mm}$ corner radius) by changing the element size.

\section{Results and discussions}

In this study, composite parts of various shapes were produced and FE models were developed in order to predict process-induced deformations. The predictions
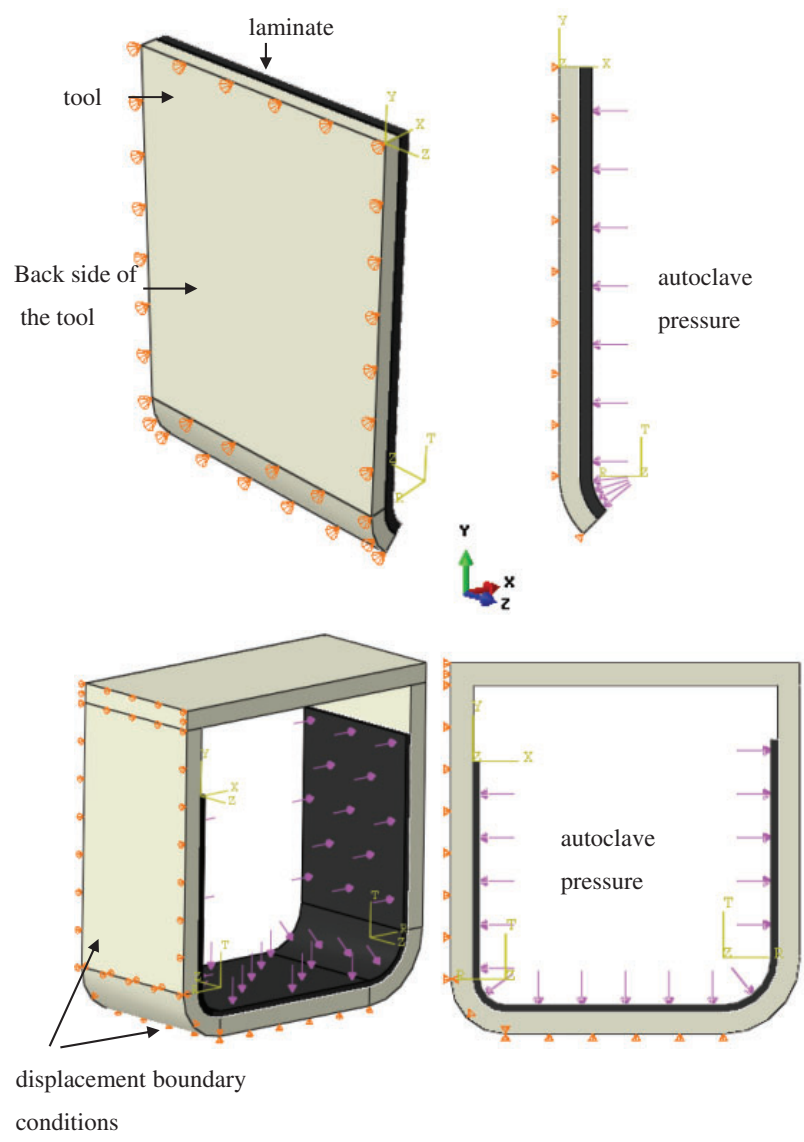

Figure 5. Loading and boundary conditions for $L$ and $U$-section parts.

and measurements were then compared to assess the validity of the assumptions behind the model. In this context, various experiments were carried out to determine how the amount of deformation was affected by factors such as the manufacturing method, thickness of the laminate, and stacking sequence of the laminate. The specimen designation is as follows: UD16-R15 is a 16-ply unidirectional laminate produced at a $15-\mathrm{mm}$ radius, and XP16-R15 is a 16-ply cross-ply laminate produced at a $15-\mathrm{mm}$ radius.

\section{Corner thickening}

The full field thickness profiles of thicker parts manufactured under a resin bleeding condition were obtained. The corner thickening can be seen easily from the scanned 16-ply thick parts in Figures 7 and 8 . The missing part in the corner of Figure 8 is due to a cut-out for microscopic examination. The resin at regions close to the corner has percolated into the corner, resulting in an increase in thickness of the corners above the nominal value. This phenomenon has also been observed by Hubert and Poursartip. ${ }^{29}$ It can 


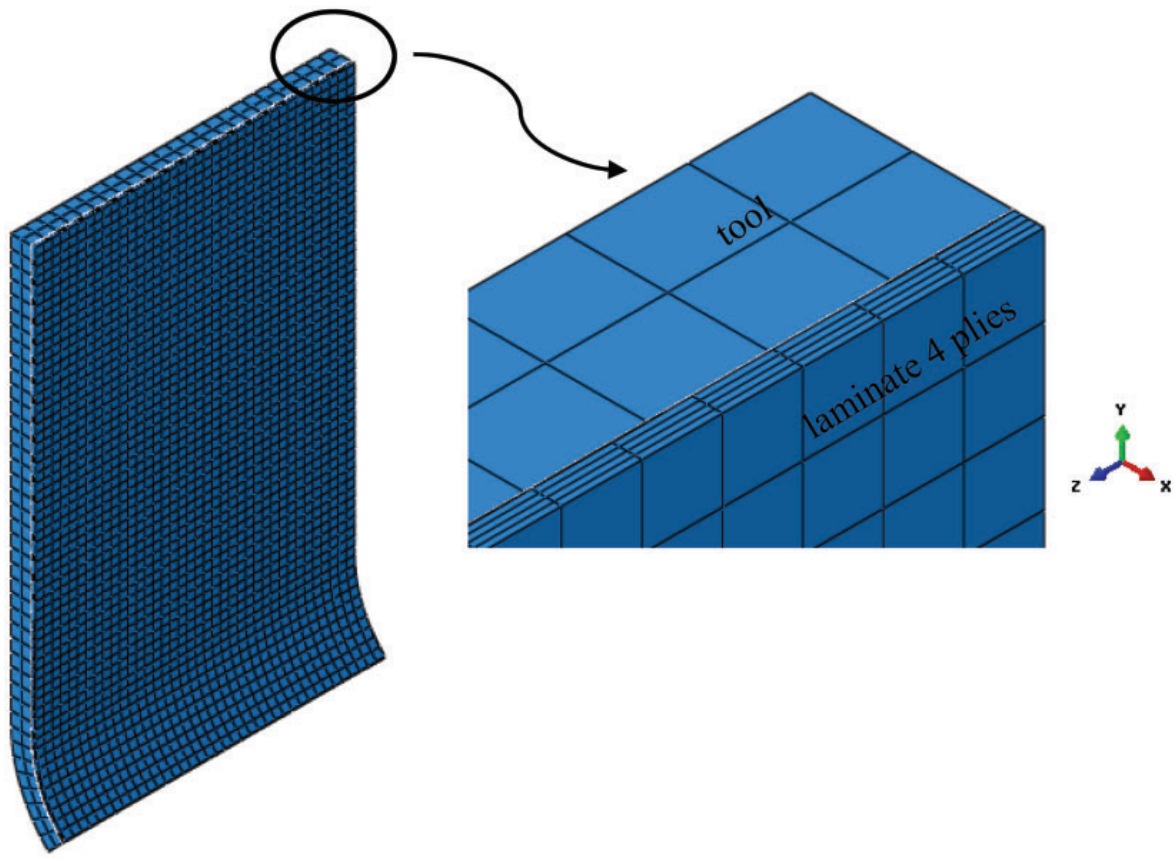

Figure 6. Finite element mesh for the tool and a 4-ply laminate.
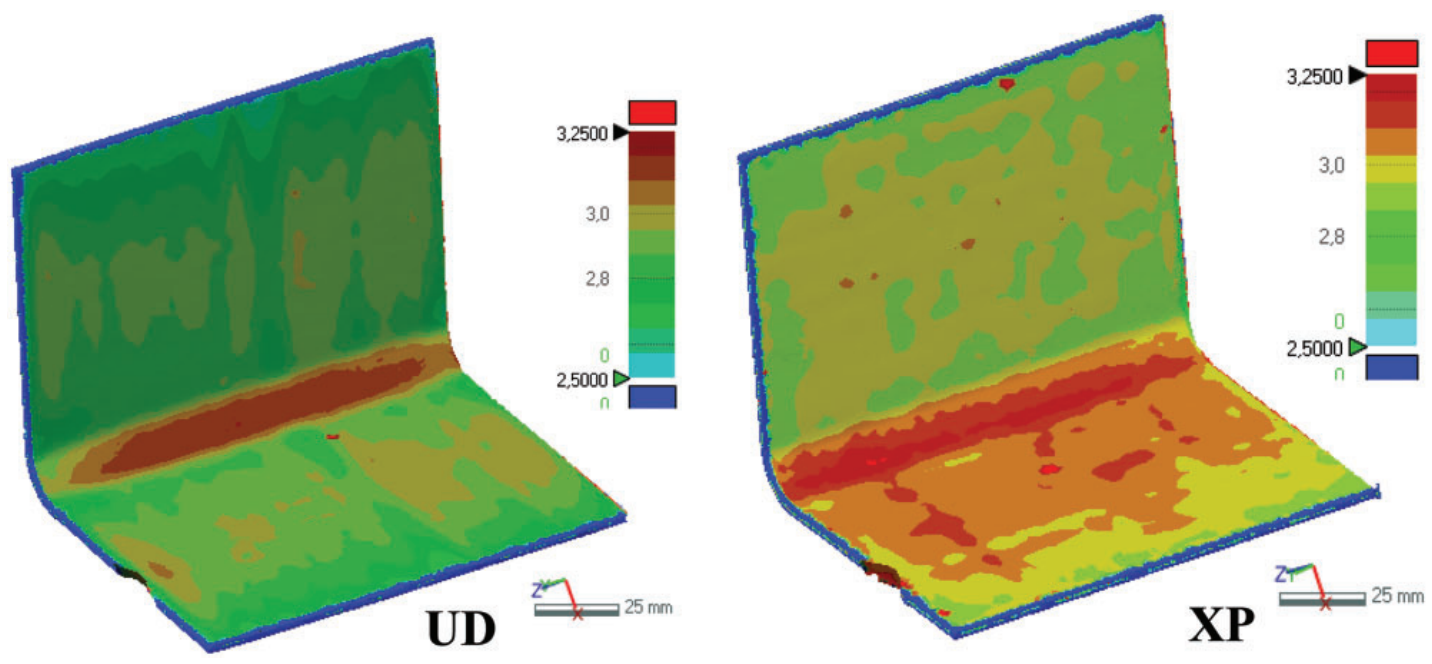

Figure 7. Thickness variation for UDI6-RI5 and XPI6-RI5 laminates. The scale is in mm.

be seen that resin bleeding is not constant along the length direction. Length direction is given in Figure 1. There was more resin bleeding at the edge of the corner, which may affect the final distortion of the part.

There is a friction between fibre layers even in the viscous state of the resin. This friction causes the fibre at the top layers not take the shape of corner, and this phenomenon is called fibre bridging. The autoclave pressure is ineffective at the corner of the part due to fibre bridging, which causes a low pressure region at the corner which is then percolated by resin so that the thickness of the part at the corner increases and a resin rich layer is formed at the surface. Fibre bridging is responsible for the non-uniform fibre volume fraction along the corner through the thickness. This effect is more pronounced in tighter radius parts.

The corner thickening from the thickness measurement at the mid-section of the laminates is represented in Figure 9. This figure shows the thickness at the midsection normalized by the nominal thickness along the part; $15 \mathrm{~mm}$ radius parts have greater corner thickening as compared to $25 \mathrm{~mm}$ radius parts. ${ }^{14}$ 

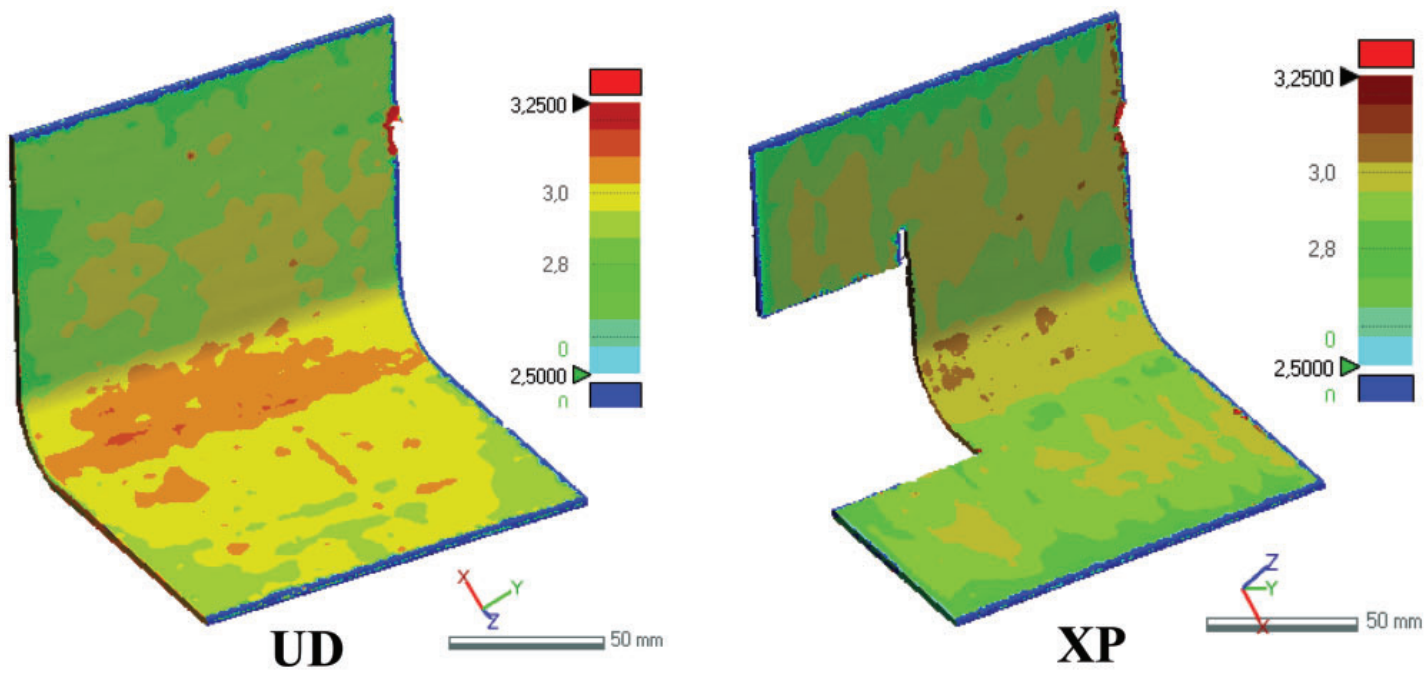

Figure 8. Thickness variation for UDI6-R25 and XPI6-R25 laminates. The scale is in mm.

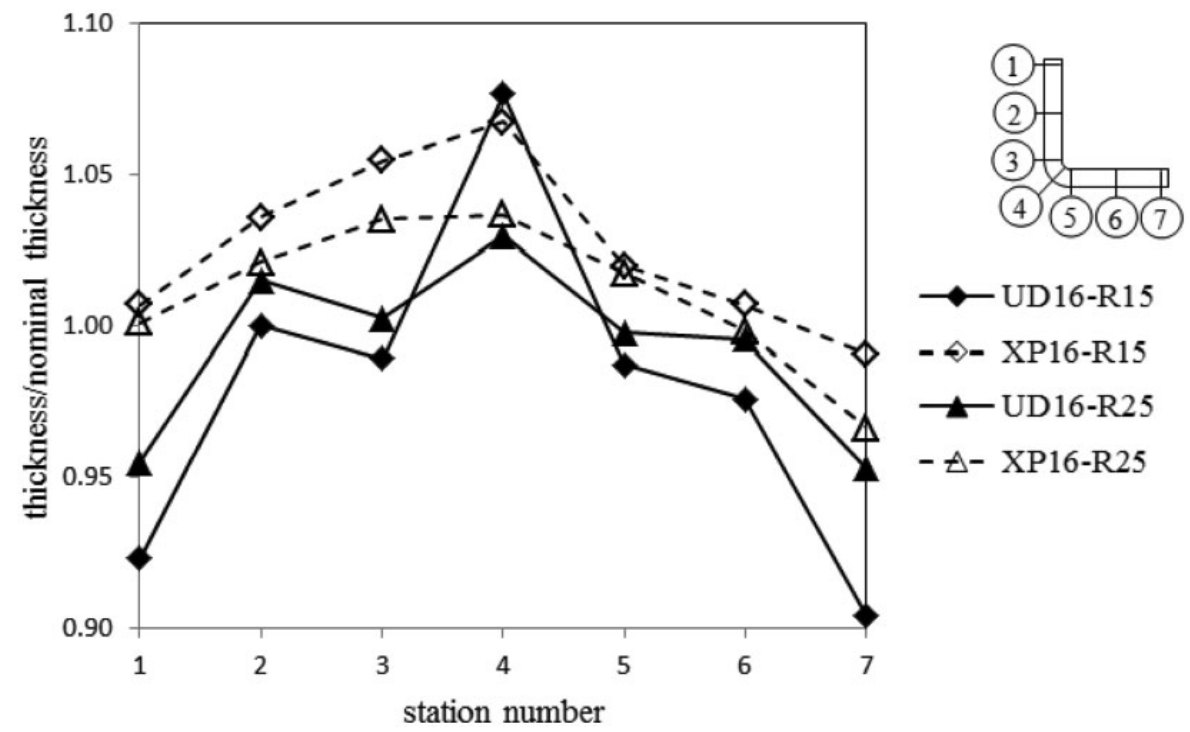

Figure 9. Thickness measurement at the mid-section of four laminates.

\section{Bagging condition}

In some applications, resin bleeding may be preferred to increase the fibre volume fraction. However, resin bleeding is also known to be a cause of shape distortion. In order to examine how resin bleeding affects the deformation, 4-ply L-shaped composite laminates were manufactured under bleeding and non-bleeding conditions. For the parts manufactured under bleeding condition, the prepreg stack was covered with a peel ply and a breather fabric before applying the vacuum bag. For the parts manufactured under non-bleeding condition, Teflon-coated glass fabric release film with a thickness of $0.08 \mathrm{~mm}$ was applied over the entire surface of the prepreg stack. Three unidirectional and cross-ply samples were manufactured on both sides of the mould under bleeding and non-bleeding condition. The details of samples manufactured are given in Table 1. Only the spring-in results of three samples (S1-S3) manufactured at R15 side of the mould is represented, which are similar to the spring-in results of samples manufactured at R25 side of the mould. After obtaining spring-in values, the comparison between these two conditions for UD4-R15 and XP4-R15 parts is made in Figures 10 and 11. Higher spring-in values were observed in the bleeding condition as compared to the non-bleeding condition, resembling the results of Darrow and Smith. ${ }^{30}$ The higher spring-in 


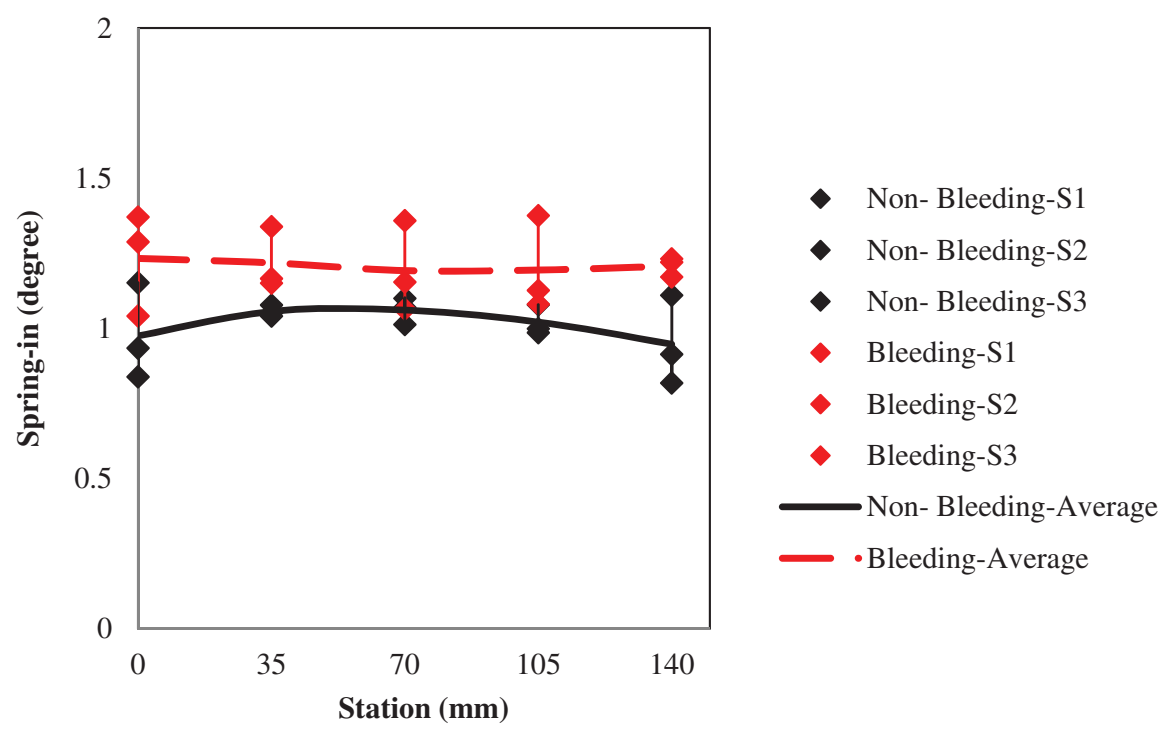

Figure 10. Measured deformation patterns in the UD4-RI5 laminate along the length direction.

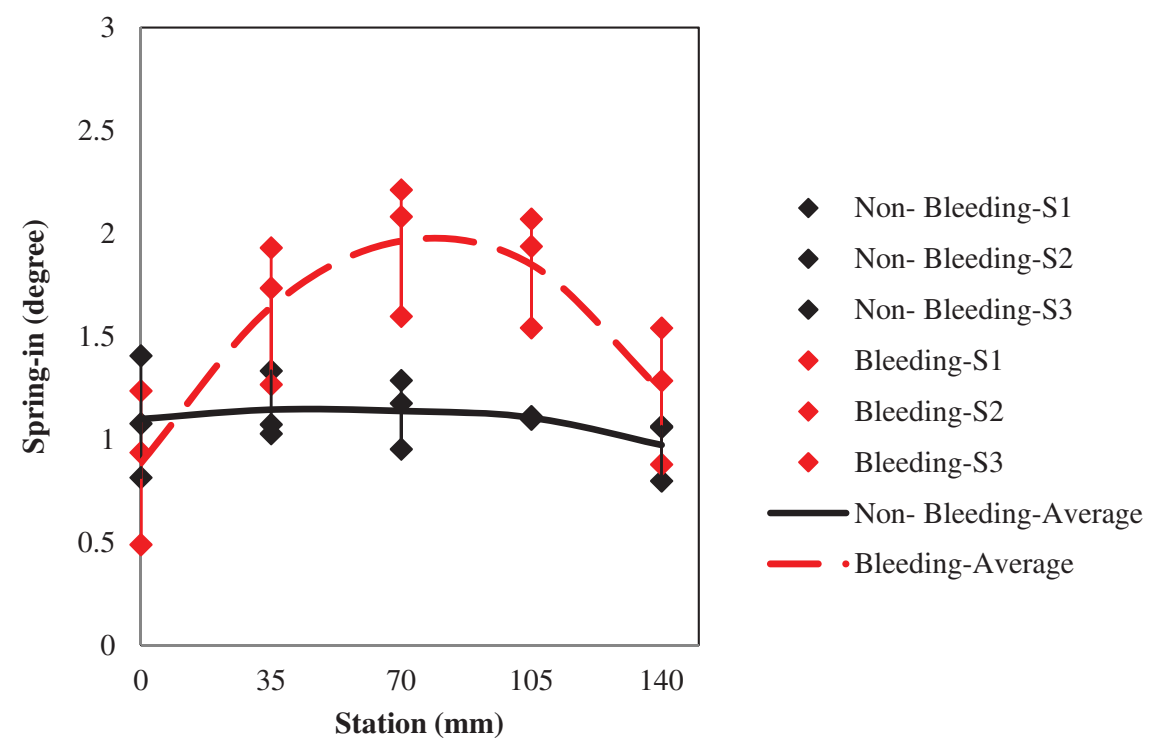

Figure II. Measured deformation patterns in the XP4-RI5 $[0 / 90]_{\mathrm{s}}$ laminate along the length direction.

came from the fibre volume fraction gradient through the thickness direction at the curved side. There was a resin rich ply at the mould surface, and a fibre rich ply at the bag surface. This contribution was only significant for thin parts where the affected region was a significant portion of the thickness of the laminate. Figure 11 also reveal that spring-in values deviated through the length direction in the cross-ply laminates under bleeding condition. The reason for this deviation was that the tool-part interaction along the length direction resulted in warpage of the XP parts, which in turn changed the spring-in values. Another possible explanation is the side bleeding in the length direction in the $90^{\circ}$ layers aligned with this direction. These mechanisms were more pronounced in the parts manufactured under bleeding condition.

The thickness profiles measured by full field measurement method are shown in Figures 12 and 13. The thickness was less in the arm close to the vacuum port in the bleeding condition. There was internal percolation to the corner in the non-bleeding condition, which reduced tension on the fibres close to the bag-side surface in the corner region. Through-thickness bleeding increased compaction in the corner region, and increased fibre tension on the fibres close to the bagside surface in the corner region. 


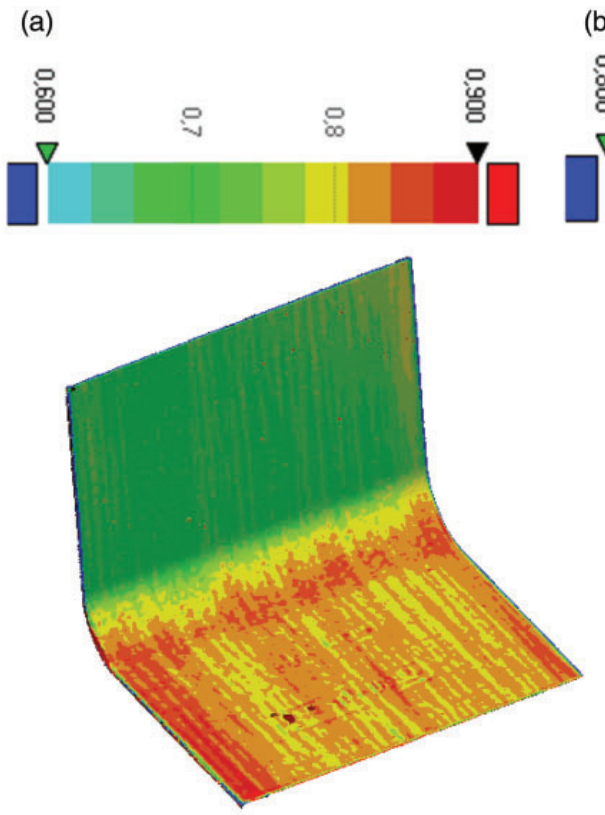

Bleeding

(b)
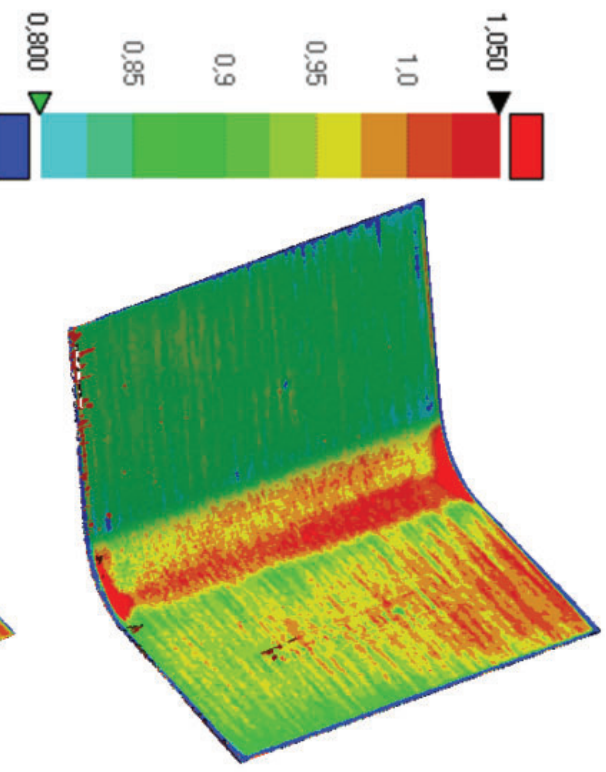

Non- bleeding

Figure 12. Thickness variation for UD4-R25 laminate. The scale is in $\mathrm{mm}$.

(a)

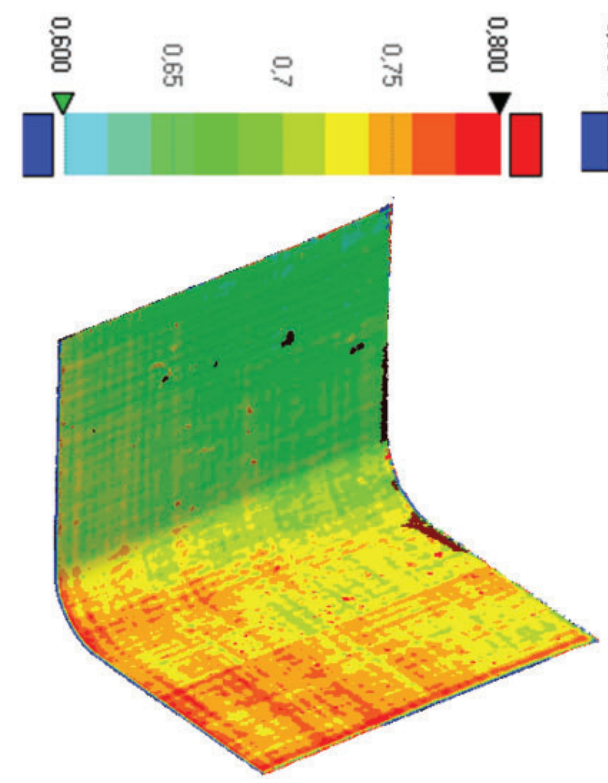

Bleeding

(b)
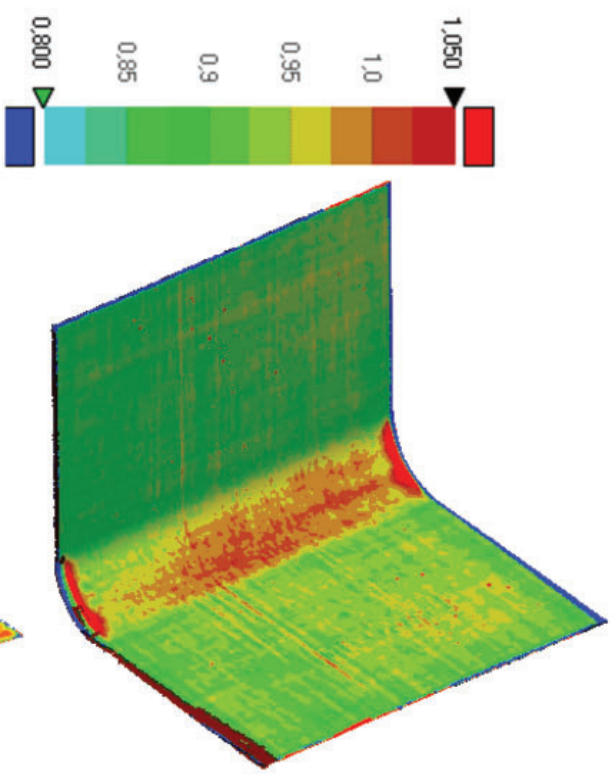

Non-bleeding

Figure 13. Thickness variation for XP4-R25 $[0 / 90]_{\mathrm{s}}$ laminate. The scale is in $\mathrm{mm}$.

\section{Effect of stacking sequence on the warpage}

The effect of stacking sequence on the distortion can be seen in L-shaped laminates by examining the warpage of the arms along different sections, e.g., along Section 1 and Section 2 as represented in Figure 14. The stacking sequence configuration is also shown in the same figure. In order to find warpage, gap distances were 


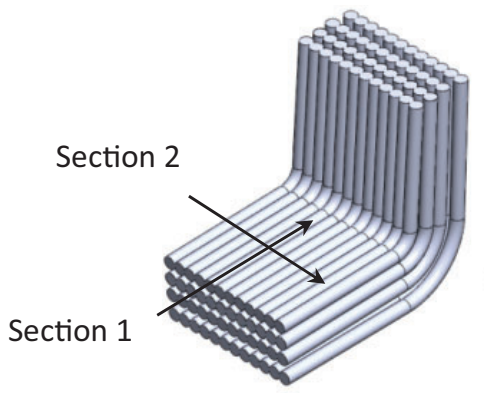

$[0]_{4}$

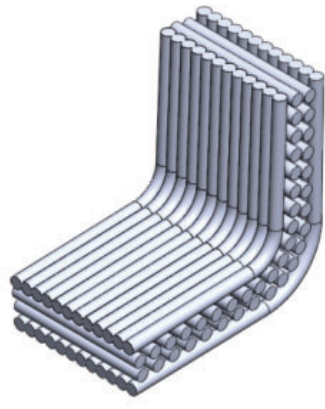

$[0 / 90]_{s}$

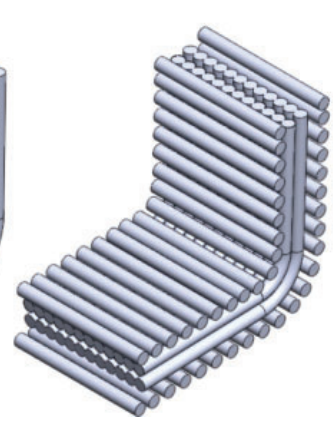

$[90 / 0]_{s}$

Figure 14. Warpage values are measured in Section I and Section 2.

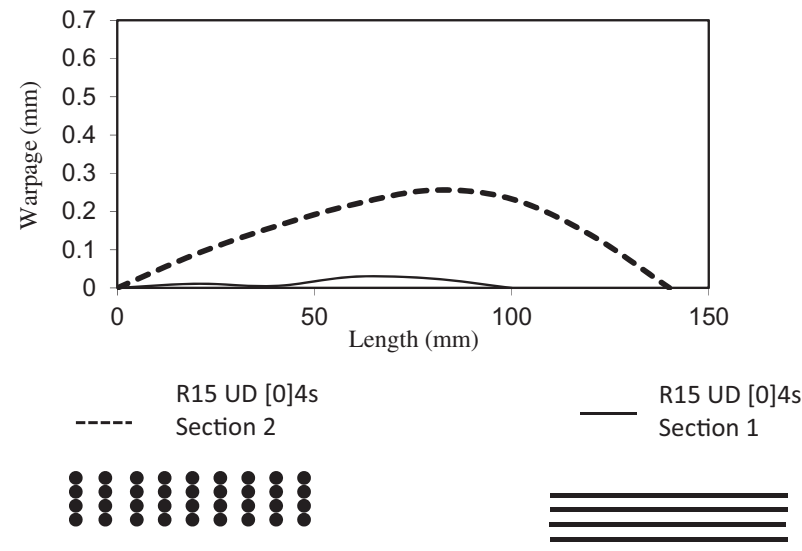

Figure 15. Warpage values measured along Section I and Section 2 for UD-RI5 $[0]_{4}$ laminate.

read at five equally spaced points along Section 1 and Section 2.

The following data were taken from the laminates that were manufactured under bleeding condition where the warpage values were higher. A comparison of warpage values between Section 1 and Section 2 shows that the warpage values along Section 2 are higher than Section 1 for $[0]_{4}$ samples, as shown in Figure 15. The bending stiffness in Section 1 (the fibre-dominated section) was higher than Section 2.

The same comparison was made for cross-ply parts of different stacking sequences. For the cross-ply laminates with the $[0 / 90]_{\text {s }}$ stacking sequence, Section 2 had more warpage than Section 1. By contrast, it was observed that Section 1 gives more warpage for the $[90 / 0]_{\mathrm{s}}$ stacking sequence. This is indicated in Figures 16 and 17.

The effect of stacking sequence on angular distortion such as spring-in was also measured for different crossply parts. The part with the $[90 / 0]$ s stacking sequence spring-out and gave negative spring-in values. The displacement of the part with respect to the tool can be seen in Figure 18 for the [0/90]s laminate and in Figure 19 for the [90/0]s laminate, where negative displacement values represent spring-in.

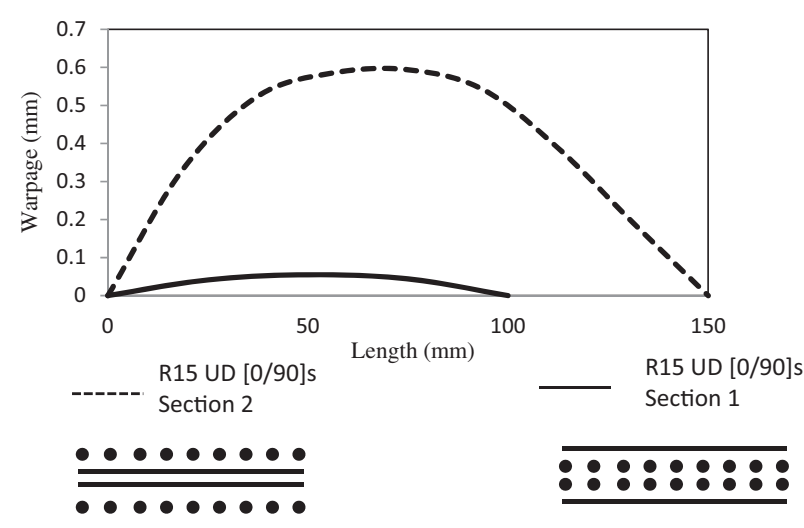

Figure 16. Warpage values measured along Section I and Section 2 for XP-RI5 [0/90]s laminate.
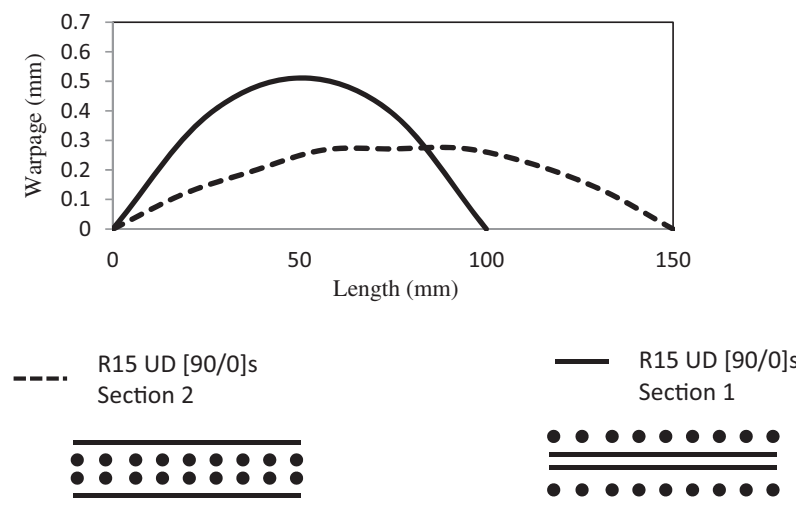

Figure 17. Warpage values measured along Section I and Section 2 for XP-RI5 [90/0] laminate.

\section{Comparison of predicted and measured 3D distor- tion patterns}

A three-step 3D FE model that included anisotropy in the thermal expansion coefficient, cure shrinkage, consolidation, and tool-part interaction was developed to predict the process-induced stresses and deformations. 

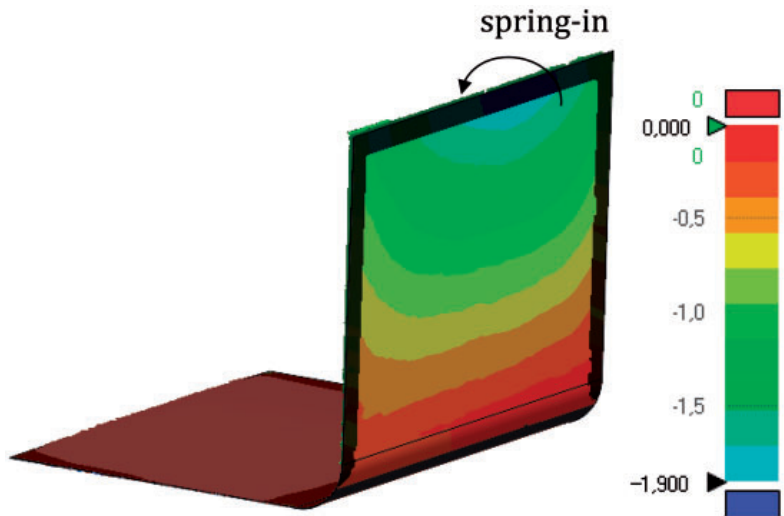

Figure 18. Spring-in values for XP-RI5 $[0 / 90]_{s}$ laminate. Scale is in $\mathrm{mm}$.
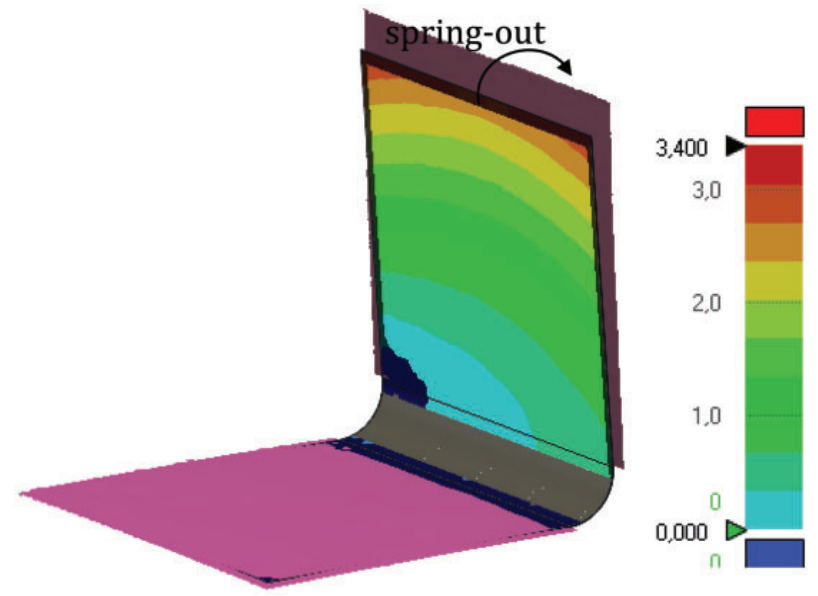

Figure 19. Spring-out values for XP-RI5 [90/0]s laminate. Scale is in $\mathrm{mm}$.
This three-step FE model was implemented to predict the shape distortion of both L- and U-shaped parts. Since the effect of the viscous shear modulus on the deformation had already been examined in the 2D FEA, ${ }^{14}$ the shear modulus in the viscous state was reduced in the current 3D FEA. Specifically, the viscous shear modulus was assumed to be one-fifth of the rubbery shear modulus. In the following subsections, the distortion predictions obtained by the 3D FE method (FEM) are compared to experimental measurements for unidirectional and cross-ply parts of various thicknesses and geometries.

Calibration of tool-part interaction parameters. As opposed to thicker parts, single ply parts give spring-out values due to the tool-part interaction effect. As the thickness of the laminate decreases, the effect of tool-part interaction on distortion increases. By using this fact, a single ply part can be manufactured and compared with the FEM results to calibrate the Coulomb friction model parameters related to tool-part interaction, such as $\mu$ and $\tau_{\max }$. Full field deformation patterns for the manufactured and predicted single ply part are shown in Figure 20. The measured tip deflection values through the length direction were well matched by the predicted ones. The calibrated properties $\mu$ and $\tau_{\max }$ were found to be 0.3 and $0.1 \mathrm{MPa}$ in viscous state and 0.3 and $0.2 \mathrm{MPa}$ in the rubbery state, respectively. The tool-part interaction was examined in detail by Garstka ${ }^{24}$ by means of an instrumented ply technique for the same material, and in the separate parametric study of Çinar et al. ${ }^{14}$ It was found that when the resin is in the viscous state, the tool-part interaction is due to fibre friction, and a sliding friction with a constant shear stress of $0.1 \mathrm{MPa}$ prevails. However, when the
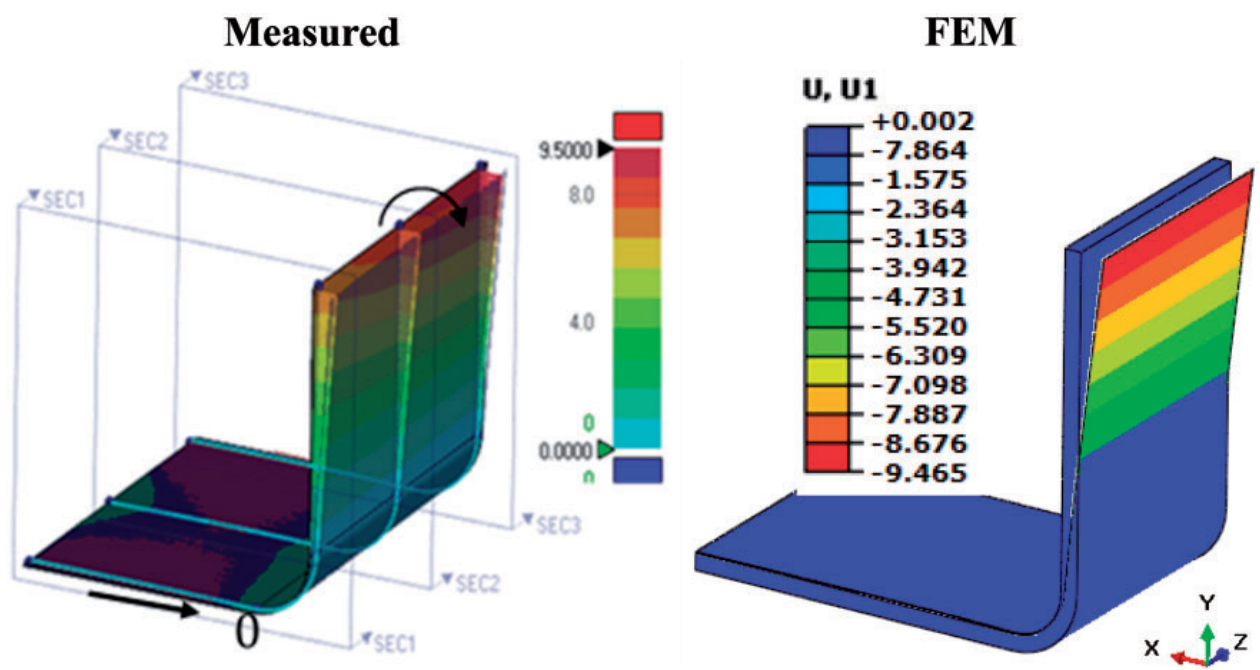

Figure 20. Predicted and measured spring-in values for the single ply part. The scale is in $\mathrm{mm}$. 

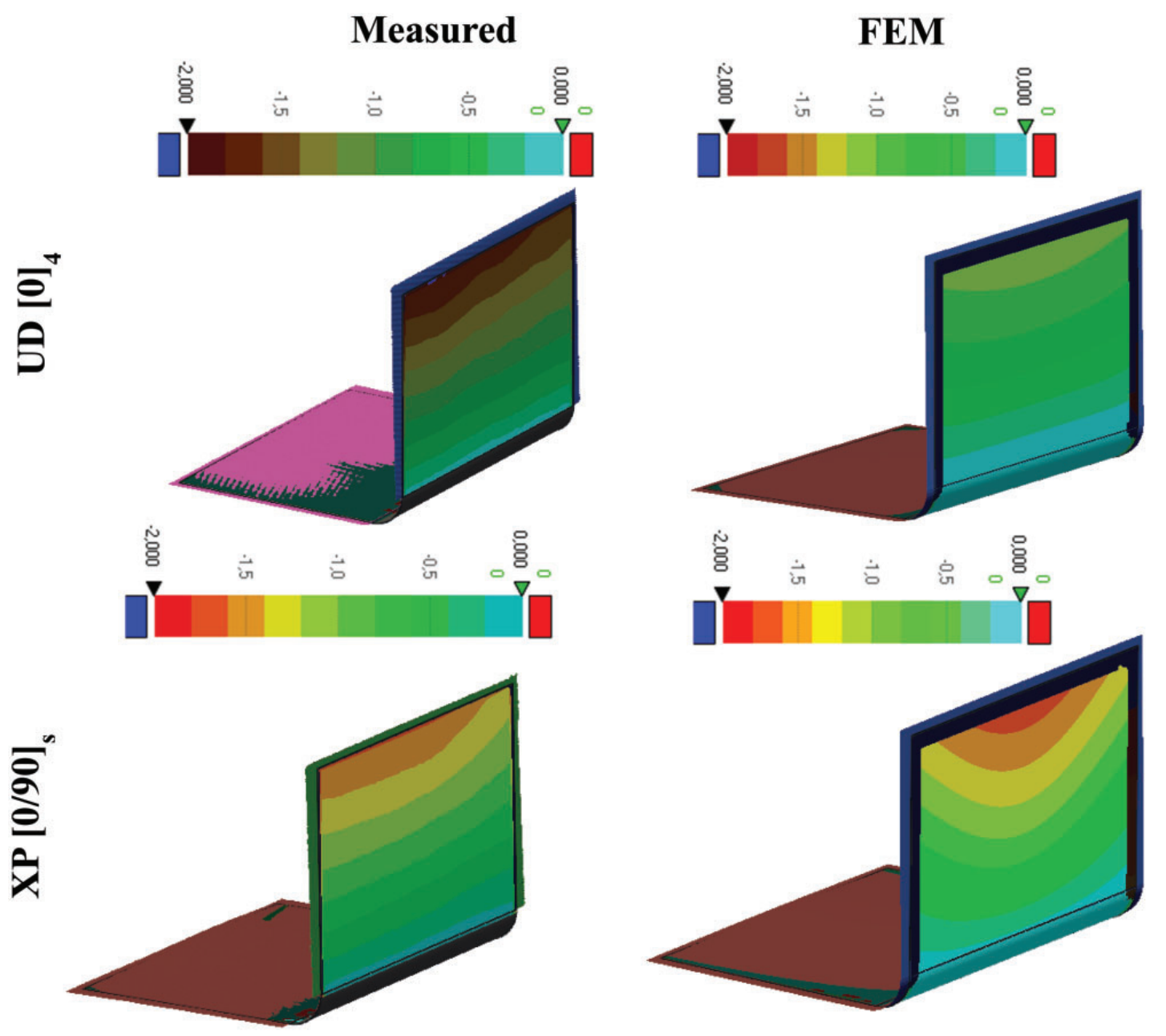

Figure $2 \mathrm{I}$. Measured and predicted deformation patterns for $[0]_{4}$ and $[0 / 90]_{\mathrm{s}} \mathrm{L}$-section parts with $\mathrm{R} / 5 \mathrm{~mm}$ corner radius. FEM: finite element method. The scale is in $\mathrm{mm}$.

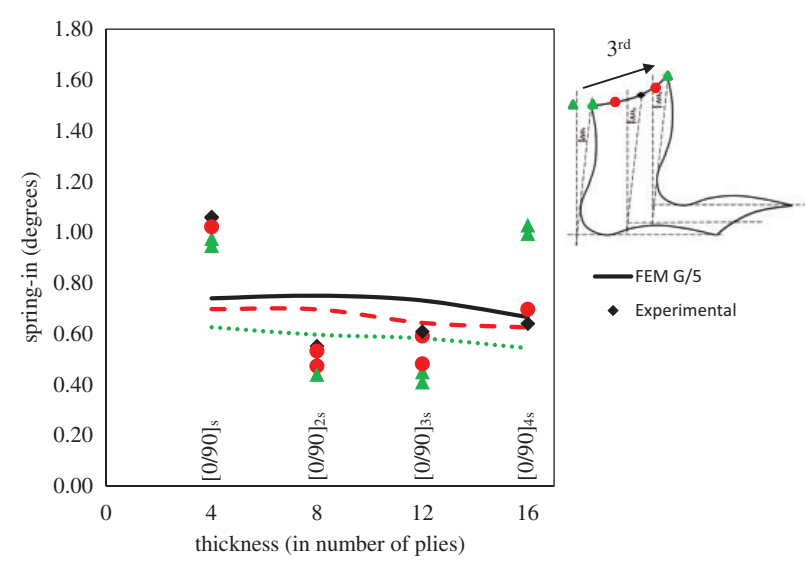

Figure 22. Spring-in predictions for UD-RI5 parts. FEM: finite element method.

resin gels, the interaction changes to a stick-slip type, resulting in a stable sliding state with a constant shear stress of $0.2 \mathrm{MPa}$ at the interface. The calibrated values

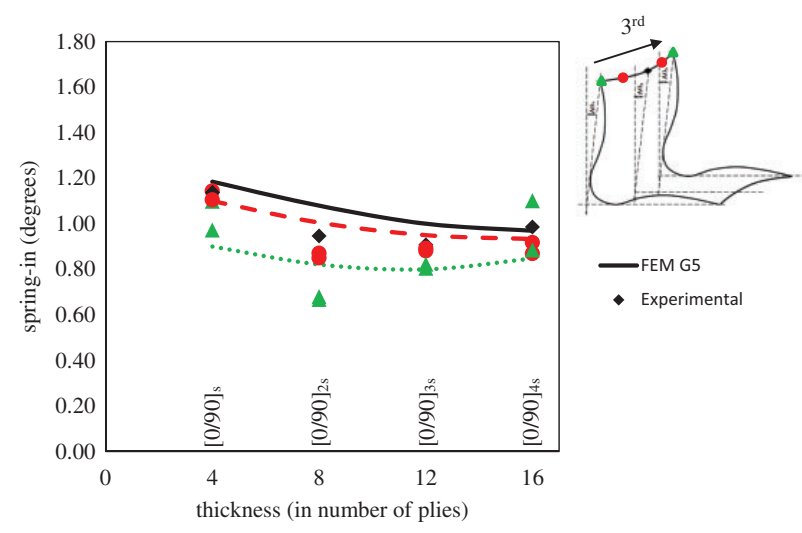

Figure 23. Spring-in predictions for XP-RI5 parts. FEM: finite element method.

were consistent with the findings of previous studies. ${ }^{14,24}$ These calibrated values were then used in the model. 


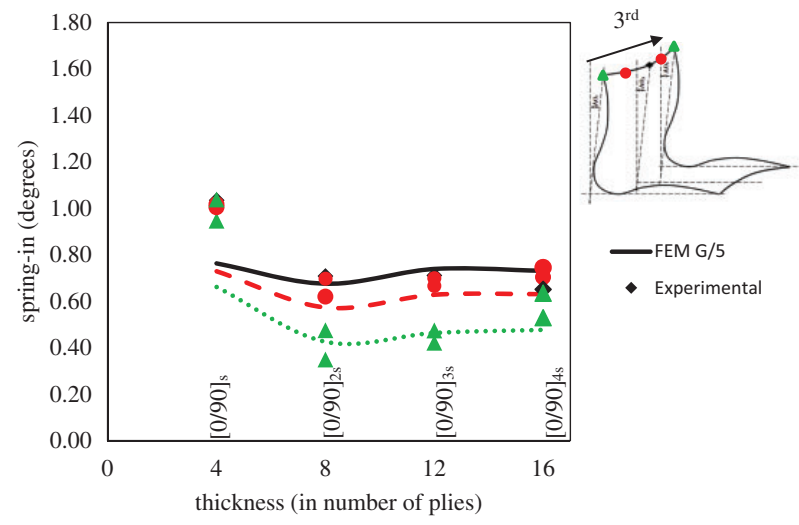

Figure 24. Spring-in predictions for UD-R25 parts. FEM: finite element method.

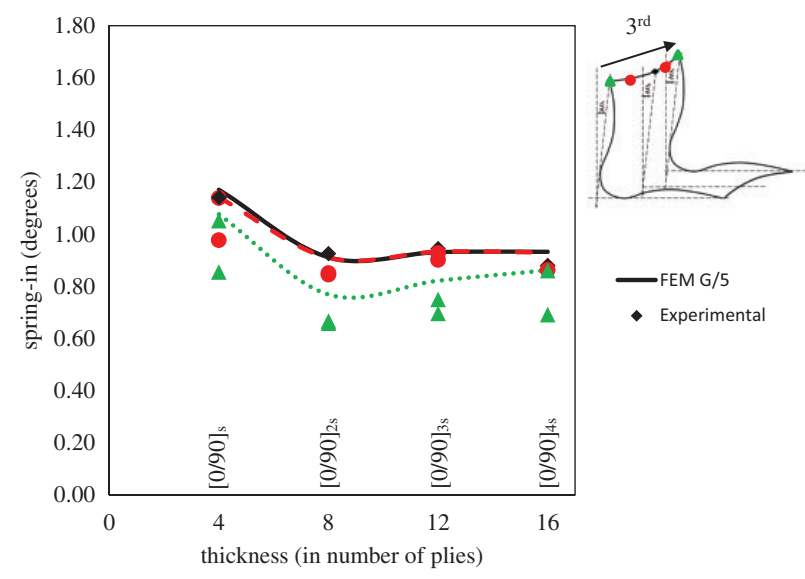

Figure 25. Spring-in predictions for XP-R25 parts. FEM: finite element method.
Comparison of predicted and measured 3D distortion patterns for L-section parts. In Figure 21, the full field deformation patterns for the UD4-R15 and XP4-R15 parts are represented. The spring-in values are plotted against the number of plies in Figures 22 to 25. The continuous and dashed lines in the figures represent the spring-in values obtained from FEA, and the markers represent the measured spring-in data on five equally spaced sections. The black markers indicate the midsection spring-in value, and the green ones indicate the edge spring-in values. The 4-ply thick parts represented in Figures 22 to 25 were manufactured under non-bleeding condition, and the other parts with 8 , 12, 16 plies were manufactured under bleeding condition.

The shear modulus reduction in the viscous state decreased the spring-in values, and hence the predictions captured the measured spring-in values quite well. The 3D FEM also captured the deformation along the third direction, which the 2D model is incapable of predicting. Finally, it can be concluded that the spring-in goes to asymptotic values as the thickness of the laminate increases, as seen in Figures 22 to 25.

Comparison of predicted and measured 3D distortion patterns for U-section parts. U-shaped UD and XP parts were modelled. The length of the parts was $500 \mathrm{~mm}$. These long U-section parts were manufactured under a nonbleeding condition. For the UD sample, the predictions are quite well when compared to the spring-in values and deformations along the third direction. The full field deformation patterns for the UD4 $[0]_{4}$ sample, as
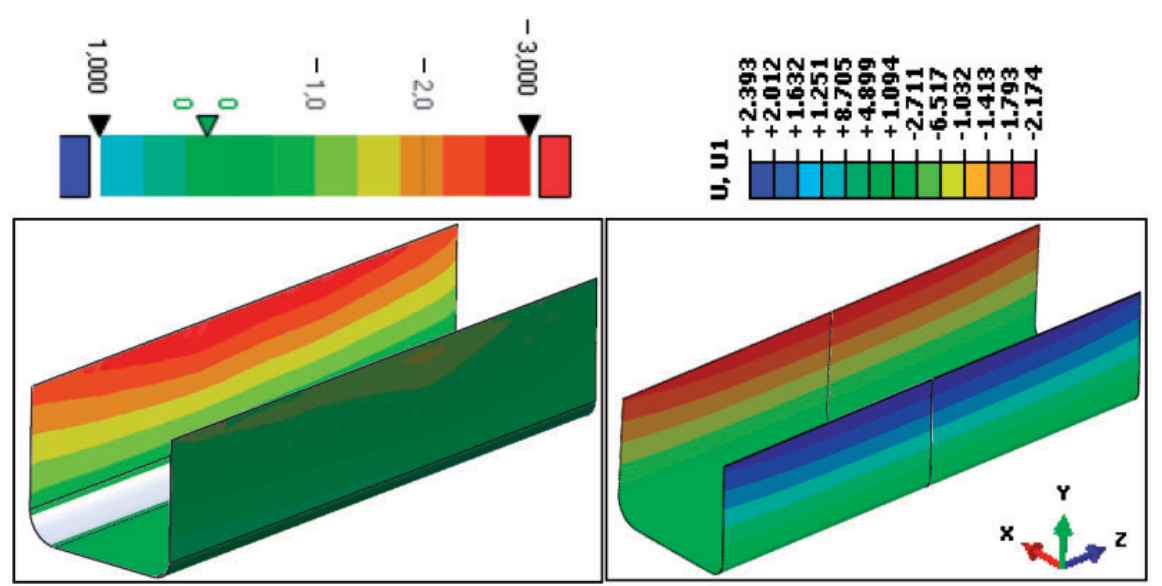

Figure 26. Measured and predicted full field deformation patterns for long U-shaped $[0]_{4}$ parts. The scale is in $\mathrm{mm}$. 

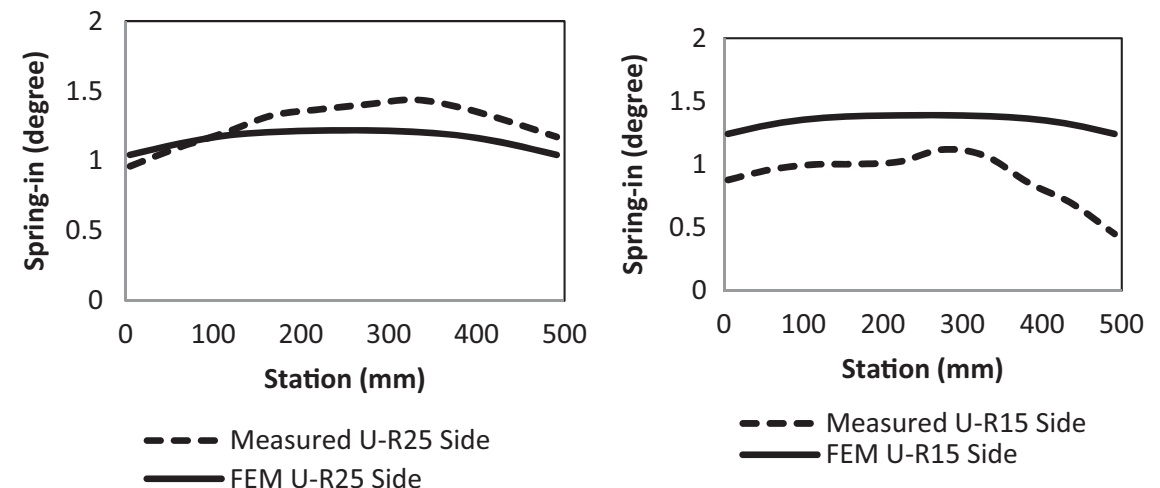

Figure 27. Spring-in predictions for long U-shaped UD4 parts. FEM: finite element method.
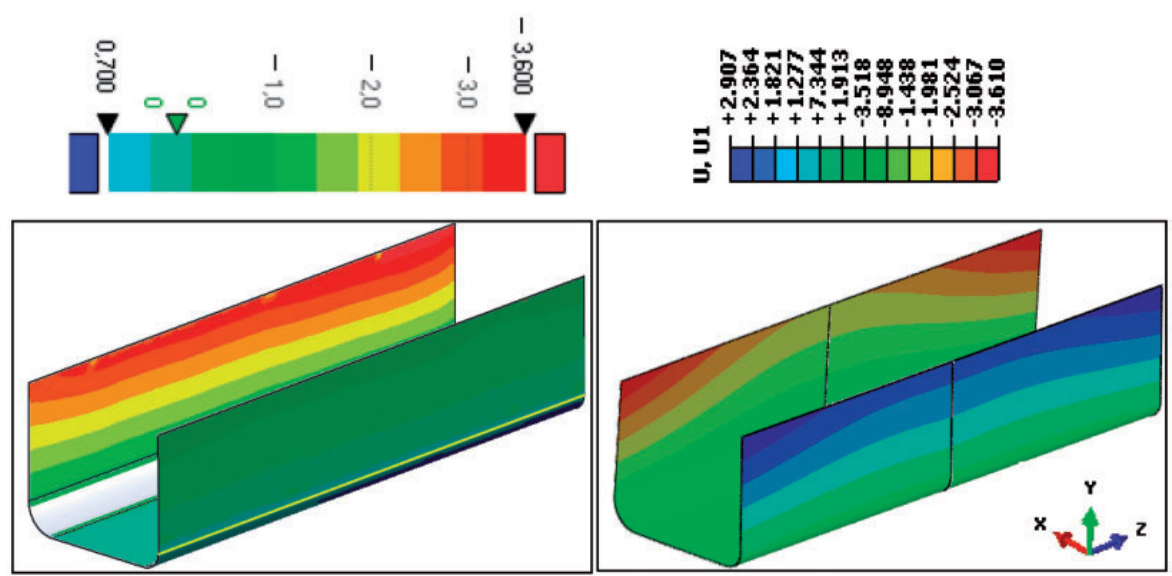

Figure 28. Measured and predicted full field deformation patterns for long $U$-shaped $[0 / 90]_{s}$ part. The scale is in $\mathrm{mm}$.
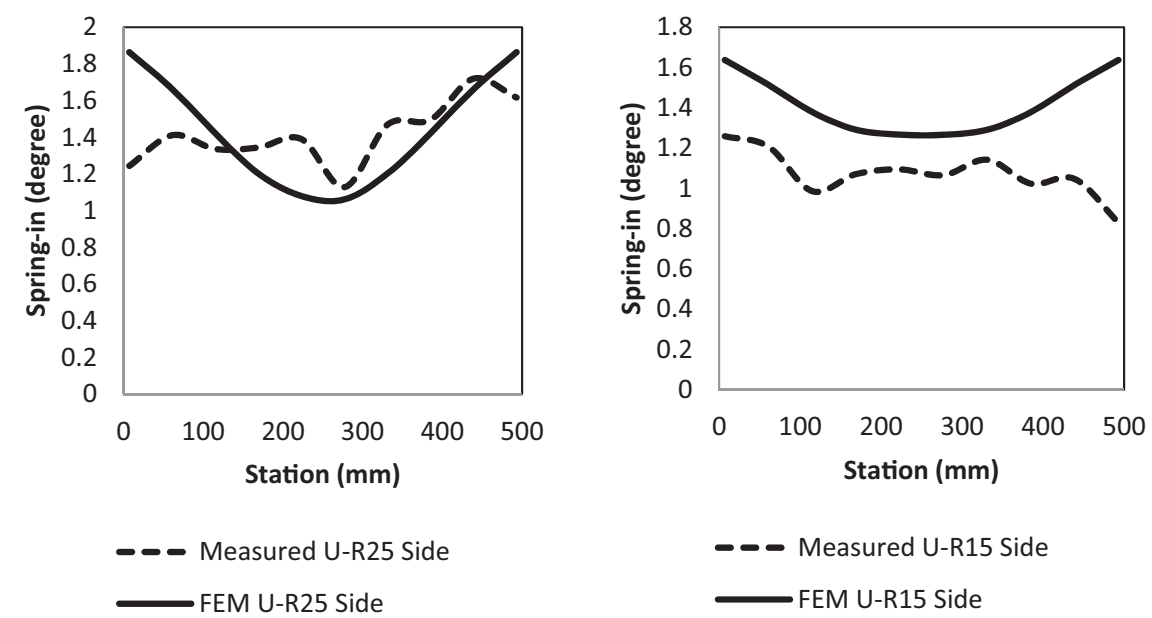

- - Measured U-R15 Side

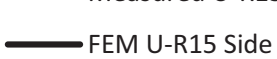

Figure 29. Spring-in predictions for long $U$ shaped XP4 $[0 / 90]_{s}$ part. FEM: finite element method. 
obtained from FEM as well as measured by laser scanner, are given in Figure 26. The spring-in values and the deformation along the third direction can be seen in Figure 27.

The full field deformation patterns for the XP4 [0/ 90] sample, as obtained from FEM as well as measured by laser scanner, are given in Figure 28. The spring-in values and the deformations along the third direction can be seen in Figure 29. For the XP sample, the springin predictions are quite well at the mid-section of the part. The spring-in was higher at the edges of the part as compared to the mid-section of the part.

\section{Conclusion}

Observations of manufactured composite parts show that the deformation of L- and U-shaped parts is not constant along the length direction, meaning that a $2 \mathrm{D}$ section with a plain strain (or generalized plane strain) model does not represent the true nature of the part. A three-step 3D model was developed to predict the shape distortions for L- and U-section parts with different stacking sequences and thicknesses. The model captured the full field deformation pattern satisfactorily. The model performs the best for the thick parts. Thin parts are more prone to effects of prepreg variability, fibre misalignment, and tool-part interaction, so the actual measurements reflect much variability for the thin parts. Variability is an inevitable phenomenon during manufacturing of composite laminates due to hand cutting and hand lay-up process, as well as the intrinsic variability even in the same batch of prepreg material, so the number of samples may be increased for variability analysis, which is beyond the scope of this work. A new method was introduced for the calibration of tool-part interaction properties $\mu$ and $\tau_{\max }$ used in the Coulomb friction model. Also, the effect of the bagging condition on the thickness distribution, and the effect of stacking sequence under bleeding condition were examined. Spring-in values were found to be higher in the parts that were manufactured under bleeding condition.

\section{Declaration of Conflicting Interests}

The author(s) declared no potential conflicts of interest with respect to the research, authorship, and/or publication of this article.

\section{Funding}

The author(s) disclosed receipt of the following financial support for the research, authorship, and/or publication of this article: Nuri Ersoy and Kenan Çınar acknowledge the support of the Boğaziçi University Research Fund and Istanbul Development Agency (ISTKA) under project codes 10020 15A60D3 and ISTKA/BIL/2012/58, respectively.

\section{References}

1. Wisnom MR, Gigliotti M, Ersoy N, et al. Mechanisms generating residual stresses and distortion during manufacture of polymer-matrix composite structures. Compos A 2006; 37: 522-529.

2. White SR and Hahn HT. Process modelling of composite materials: residual stress development during cure. Part I. Model formulation. $J$ Compos Mater 1992; 26: 2423-2453.

3. White SR and Hahn HT. Process modelling of composite materials: residual stress development during cure. Part II. Experimental validation. J Compos Mater 1992; 26: 2423-2453.

4. Bogetti TA and Gillipse JW. Processing-induced stress and deformation in thick section thermosetting composite laminates. CCM Report 89-21, University of Delaware, Newark, DE, August 1989.

5. Bogetti TA and Gillespie JW Jr. Process-induced stress and deformation in thick-section thermoset composite laminates. J Compos Mater 1992; 26: 626-660.

6. Loos AC and Springer GS. Curing of epoxy matrix composites. J Compos Mater 1983; 17: 135-169.

7. Arafath ARA, Vaziri R and Poursartip A. Closed-from solution for process-induced stresses and deformation of a composite part cured on a solid tool: Part I - flat geometries. Compos A 2008; 39: 1106-1117.

8. Arafath ARA, Vaziri R and Poursartip A. Closed-from solution for process-induced stresses and deformation of a composite part cured on a solid tool: Part II - curved geometries. Compos A 2009; 40: 1545-1557.

9. Johnston A, Vaziri R and Poursartip A. A plane strain model for process-induced deformation of laminated composite structures. J Compos Mater 2001; 35: 1435-1469.

10. Svanberg JM and Holmberg JA. An experimental investigation on mechanisms for manufacturing induced shape distortions in homogeneous and balanced laminates. Compos A 2001; 32: 827-838.

11. Svanberg JM, Altkvist C and Nyman T. Prediction of shape distortions for a curved composite C-spar. J Reinf Plast Compos 2005; 24: 323-339.

12. Svanberg JM and Holmberg JA. Prediction of shape distortions. Part II. Experimental validation and analysis of boundary conditions. Compos A 2004; 35: 723-734.

13. Ersoy N, Garstka T, Potter K, et al. Modelling of the spring-in phenomenon in curved parts made of a thermosetting composite. Compos A 2010; 41: 410-418.

14. Çınar K, Öztürk UE, Ersoy N, et al. Modelling manufacturing deformations in corner sections made of composite materials. J Compos Mater 2014; 48: 799-813.

15. Çınar K and Ersoy N. Effect of fibre wrinkling to the spring-in behaviour of L-shaped composite materials. Compos A 2015; 69: 105-114.

16. Zhu Q, Geubelle PH, Li M, et al. Dimensional accuracy of thermoset composites: simulation of process-induced residual stresses. J Compos Mater 2001; 35: 2171-2205.

17. Clifford S, Jansson N, Yu W, et al. Thermoviscoelastic anisotropic analysis of process induced residual stresses and dimensional stability in real polymer matrix composite components. Compos A 2006; 37: 538-545. 
18. Tavakol B, Roozbehjavan P, Ahmed A, et al. Prediction of residual stresses and distortion in carbon fiber-epoxy composite parts due to curing process using finite element analysis. J Appl Polym Sci 2013; 128: 941-950. (DOI: 10.1002/app.38075).

19. Wucher B, Lani F, Pardoen T, et al. Tooling geometry optimization for compensation of cure-induced distortions of a curved carbon/epoxy C-spar. Compos A 2014; 56: 27-35.

20. Dong C. Modeling the process-induced dimensional variations of general curved composite components and assemblies. Compos A 2009; 40: 1210-1216.

21. Kappel E, Stefaniak D, Sprowitz T, et al. A semi-analytical simulation strategy and its application to warpage of autoclave-processed CFRP parts. Compos A 2011; 42: 1985-1994.

22. Ferlund G, Rahman N, Courdji R, et al. Experimental and numerical study of the effect of cure cycle, tool surface, geometry, and lay-up on the dimensional fidelity of autoclave-processed composite parts. Compos $A$ 2002; 33: 341-351.

23. Twigg G, Poursartip A and Ferlund G. Tool-part interaction in composite processing. Part II: numerical modelling. Compos A 2004; 35: 135-141.
24. Garstka T. Separation of process induced distortions in curved composite laminates. PhD Thesis, University of Bristol, Bristol, 2005.

25. Flanagan R. The dimensional stability of composite laminates and structures. PhD Thesis, Queen's University of Belfast, Belfast, 1997.

26. ABAQUS 6.12 Online Documentation, Dassault Systèmes, Providence, RI, USA, 2012.

27. Ersoy N, Garstka T, Potter K, et al. Development of the properties of a carbon fibre reinforced thermosetting composite through cure. Compos A 2010; 41: 401-409.

28. Garstka T, Ersoy N, Potter KD, et al. In situ measurements of through-the-thickness strains during processing of AS4/8552 composite. Compos $A$ 2007; 38: 2517-2526.

29. Hubert P and Poursartip A. Aspects of the compaction of composite angle laminates: an experimental investigation. J Compos Mater 2001; 35: 2-26.

30. Darrow DA Jr and Smith LV. Isolating components of processing induced warpage in laminated composites. J Compos Mater 2001; 36: 2407-2418. 